\title{
Casos de Divórcios japoneses no Brasil: Introdução ao método de análise de casoś
}

\author{
Profa. Dra. Claudia Lima Marques, \\ Professora Titular de Direito Internacional Privado da \\ Universidade Federal do Rio Grande do Sul-UFRGS \\ Doutora em Direito (Heidelberg), Mestre em Direito \\ Internacional Privado e Direito Civil (Tübingen), \\ Alemanha.
}

Pode chamar a atenção do leitor a parte 3 da Edição Especial em Homenagem à Cooperação com a Faculdade de Direito da Universidade de Tohoku (Nordeste), Sendai, Japão, ser dedicada à pesquisa da imigração japonesa no Rio Grande do Sul e à análise de casos práticos de Direito Japonês decididos no Supremo Tribunal Federal. Em verdade, a iniciativa de introduzir uma parte mais 'prática' e metodologicamente mais 'atualizada' nesta Revista da Faculdade de Direito da UFRGS é o resultado (positivo) destas 3 visitas já ocorridas em virtude desta cooperação: duas da Professora Yuko Nishitani, da Faculdade de Direito da Universidade de Tohoku, Sendai, na UFRGS, em 1999 e 2001 e uma visita minha à Universidade de Tohoku, no Japão, em fevereiro de 2002. ${ }^{1}$

\footnotetext{
1 Graças ao gentil convite da Profa. Dra. Yuko Nishitani e do Diretor da Faculdade de Direito de Tohoku, Sendai, que também estudou na Alemanha, Prof. Dr. Shoji Kawakami, pude realizar 3 palestras no Japão, na Universidade de Tohoku, Sendai, na Faculdade de Direito de Kyoto e na Faculdade de Direito de Tóquio, assim como participar por duas vezes do grupo de estudos em Direito Internacional Privado do Prof. Sakurada (Kyoto). Minhas palestras, que foram traduzidas para o japonês pela Profa. Dra. Yuko Nishitani, o que muito agradeço, foram as seguintes: 1. Proteção do consumidor no Brasil : O Código Brasileiro de Defesa do Consumidor em visão comparatista (Verbraucherschutz inBrasilien : Das brasilianische Verbraucherschutzgesetz von 1990 aus rechtsvergleichender Sicht) 2. Proteção internacional do consumidor e o comércio eletrônico no direito brasileiro: a proteção contratual (Internationaler Verbraucherschutz und elektronischer Kommerz im brasilianischen Recht : vertraglicher Schutz) e 3. Desenvolvimento e Reforma da adoção internacional no direito braisleiro: a Convenção de Haia de 29 de maio de 1993 (Entwicklung und Reformen der brasilianischen internationalen Adoptionsrecht: das Haaguer Übereinkommen vom 29. Mai 1993), esta última reproduzida nesta edição especial.- unter besonderer Berücksichtigung US-amerikanischer punitive damages-Urteile -", ministrada dia 12.05.1999, e, em 2001, "Einführung ins japanische Recht II: unter besonderer Berücksichtigung des Gesetzes über Verbraucherverträge", e "Scheidung brasilianischer Staatsangehöriger in Japan".
} 
Se na primeira visita da colega japonesa, Professora Nishitani, à UFRGS, a tônica dos trabalhos foi a Introdução ao Direito Japonês e a seu Direito Internacional Privado, e, na segunda, foram as mudanças no direito civil, comercial e do consumidor no Japão, ${ }^{2} \mathrm{As}$ suas palestras, em alemão, foram: "Einführung ins japanische Recht", ministrada dia 11.05.1999 e "Anerkennung und Vollstreckung ausländischer Urteile in Japan

aproveitamos o espaço de 2 anos entre uma visita e outra para realizar uma pesquisa conjunta, sobre casos em que os juristas brasileiros se vissem confrontados com a aplicação do Direito Japonês.

Seguindo as orientações de nosso mestre comum, o Prof. Dr. Erik Jayme da Universidade de Heidelberg, Alemanha, em seu artigo sobre Direito Comparado pósmoderno, ${ }^{3}$ escolhemos como objeto de pesquisa as 'diferenças', ${ }^{4}$ especialmente em Direito Internacional de Família. Em outras palavras, o direito comparado pós-moderno estaria mais interessado no diferente, no fluído e especial, aquele que divide e caracteriza, no atual e específico de cada ordenamento jurídico, a respeitar a identidade social e cultural de cada povo. ${ }^{5}$ Brasil e Japão duas culturas, dois povos diferentes, dois sistemas jurídicos. Escolhemos particularmente como objeto de pesquisa os casos de divórcio, pois aqui as diferenças são maiores: em 1999,91,46\% dos divórcios realizados no Japão foram divórcios "privados", extrajudiciais conforme determina o $\$ 764 \mathrm{c} / \mathrm{c} \$ 739$ do Código Civil Japonês (Kasai Geppô), já 7,73\% dos divórcios ocorrem por arbitragem/ mediação e somente $0,81 \%$ através de decisões judiciais stricto sensu. ${ }^{6}$ São estes divórcios "privados" japoneses que devem ser reconhecidos no Brasil, especialmente pelo Supremo Tribunal Federal e interessava saber se a sua natureza "administrativa" ou "privada" impedia ou não o seu reconhecimento no Brasil. De outro lado, no Brasil, o divórcio, como instituição, foi uma das mais polêmicas; instituição desconhecida no ordenamento jurídico brasileiro até 1977, alcançou hierarquia constitucional (sua proibição e sua liberalização), sofreu vários limites e integra hoje, sem dúvida alguma, a ordem pública em DIP, sendo um dos objetos de pesquisas em DIP mais utilizados para estudos e exemplos. ${ }^{7}$

\footnotetext{
${ }^{3}$ Veja JAYME, Erik, Visões para uma teoria pós-moderna do direito comparado, in Revista dos Tribunais (São Paulo), nr. 759 , p. 24 a 40.

4 JAYME, RT 759, p. 25: "A minha Tese principal é a seguinte: O direito comparado moderno perseguia o objetivo, de determinar, de encontrar o que era comum, igual (das Gemeinsame), e que apenas superficionalmente podia aparecer e ser percebido de forma diversa, nos também apenas superficionalmente diversos, sistemas de Direito do mundo. O direito comparado pósmoderno procura, ao contrário, o que divide(das Trennende), as diferenças (die Unterschiede)." ${ }^{5}$ Veja meu artigo, Notas sobre o sistema de proibição de cláusulas abusivas no Código Brasileiro de Defesa do Consumidor (Entre a tradicional permeabilidade da ordem jurídica e o futuro pósmoderno do direito comparado), in RTDC vol. 1, jan/mar. 2000, p. 13 a 58.

${ }^{6}$ Dados levantados por Nishitani, em 1999, veja Jinkô Dôtai Chôsa 1999 (http://wwwdbtk.mhw.go.jp/ toukei/data/010/1999/tokeihyou/0002674/ t0048025/ml...)

7 Vjea as obras brasileiras de Villela e Dolinger e o resumo atualizado no curso de Hai de DOLINGER, Jacob, Evolution of principles for resolving conflicts in the field of contracts and torts, in Recueil, vol. 283 (2000), p. 291 e seg.
} 
Assim, para a visita de 2001 foi-nos possível selecionar e compilar todos os últimos casos (posteriores à entrada em vigor da Constituição Federal de 1988, com sua nova ordem pública de Família) de divórcios japoneses reconhecidos pela Justiça brasileira. $\mathrm{O}$ resultado da pesquisa foi tão interessante que resolvemos renová-la em 2002 e, nesta terceira visita à UFRGS, a Prof. Nishitani completará a análise que realizou em 2001, motivo pelo qual não incluímos seu texto nesta edição especial. Até 22 de agosto de 2002, nossas pesquisas no site do STF encontraram 30 decisões do STF envolvendo divórcios japoneses, que encontram-se reproduzidas ao final desta parte. ${ }^{8}$

Em sua palestra de 2001, a professora Nishitani resume as regras sobre o Divórcio no Direito Japonês: "O Código Civil Japonês (CCJ, Kasai Geppô) prevê o Divórcio privado e o divórcio judicial. A lei sobre Decisões em Matéria Familiar (LDMF, kaji shinpanhô) prevê o divórcio arbitral (administrativo) voluntário e o divórcio arbitral imperativo. Assim temos:

(1) Divórcio privado ( $\$ \$ 764$ e 739 CCJ) ® Deve ser registrado no "registro familiar" (koseki) conforme a Lei sobre o Registro Familiar (kosekihô)

(2) divórcio arbitral é feito no tribunal familiar (administrativo) (Prioridade do arbitramento por mediadores em caso de não consenso: Art. 18, 1 LDMF)

(3) divórcio arbitral imperativo (sobre a base do arbitramento e mediação) frente ao Tribunal (administrativo) de Família (Art. 24 LDMF) ® Há possibilidade de recurso

(4) Divórcio Judicial frente ao Juiz distrital (Processo normal segundo o Artigos 1 e seguintes da Lei processual sobre processos envolvendo direitos individuais-LPDI, jinji soshô tetsuzukihô), quando um dos motivos de divórcio do $§ 770,1$ CCJ está presente. Há um maior espaço de convencimento e decisão para o Juiz, mas a previsibilidade da decisão é pequena."

De sua palestra de 2001 retira-se também que caso um dos 220 mil brasileiros que vivem atualmente no Japão queira divorciar-se, será possivelmente declarado aplicável o direito japonês, face aos elementos de conexão escolhidos pela lei japonesa: "A Lei aplicável ao divórcio (estatuto do divórcio) segundo o Direito Internacional Privado japonês é a seguinte: Art. 16,1 da Lei de Direito Internacional Privado/Horei,

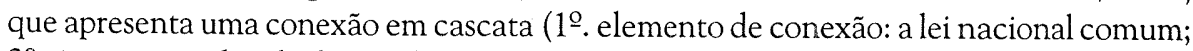
$2^{a}$ conexão: a lei do lugar de residência habitual comum; $3^{\text {a }}$ conexão: a lei mais conectada com o caso concreto/lei mais próxima do caso) e Art. 16,2 Horei: Se um dos cônjuges tem a nacionalidade japonesa e a sua residência habitual no Japão, aplicarse-á a lei japonesa (denominada cláusula de "favor japonês")." A probabilidade é grande, pois, que aplique-se a lei japonesa e tenha este divórcio privado, por arbitragem/ mediação ou judicial ser reconhecido pelo Supremo Tribunal Federal no Brasil. ${ }^{9}$

\footnotetext{
${ }^{8}$ O levantamento total apontou:

1.Decisões Monocráticas, 1.1. Homologação de Sentenças (SE): 19; a) Eficácia de certidão administrativa de divórcio: 15; b) Sentença de divórcio: 04; c) Adoção: 02; 1.2.Cartas Rogatórias (CR): $5 ; 1.3$. Outros (incluindo diligências de SE e CR): 10; 2. Acórdãos ;2.1. Homologação de Sentenças (SE): 6; 2.2. Outros: 4

9 Veja,por todos, MARUTSCHKE, Einführung in das japanische Recht, Munique, Beck, 1999, p.

2 e seg.
} 
Neste sentido, com a ajuda de nossas pesquisadoras do Grupo de Pesquisa CNPq "Mercosul e Direito do Consumidor", Maitê Schmidt (bolsista de IC Propesq/UFRGS) e a mestranda Daniela Jacques (CAPES) realizamos o levantamento de todas as decisões do STF e publicaremos ao final desta quarta parte todas as decisões levantadas até agosto de 2002. Da mesma forma, para tornar mais didática a análise dos casos, incluímos dois comentários $^{10}$ a uma das decisões principais referentes à divórcio japonês no Supremo Tribunal Federal, a Sentença Estrangeira Contestada n. 6.399-0/Japão, julgada em 21.06.2000, comentários estes elaborados pelas mestrandas e alunas do Curso de Especialização em Direito Internacional, Natália Aranovich e Tomoku Kimura Gaudioso.

A metodologia do estudo de casos é um instrumento pedagógico muito usado nas Faculdades de Direito alemãs, desde as aulas especiais de trabalhos com casos (Fallbesprechungen) até as aulas magistrais (Vorlesungen) que hoje também utilizam-se ou partem de casos para melhorar o entendimento dos estudantes. Pareceu-nos interessante trazer mais esta metodologia para o ensino jurídico no Brasil. Não que seja esta desconhecida, mas que geralmente é apresentada em sua vertente mais radical socrática, o case method norte-americano ${ }^{11}$ e não na vertente mista (e parece-nos mais adaptada ao estilo jurídico brasileiro), a alemã. As ciências sociais no Rio Grande do Sul sempre sofreram forte influência da metodologia e da filosofia alemã, ${ }^{12}$ assim também o Direito. ${ }^{13}$ Dai porque pareceu-me útil incluir nesta edição especial estes resultados, mesmo que iniciais, de nossa pesquisa conjunta com a Profa. Dra. Yuko Nishitani. Esta última parte é, pois, dedicada à prática e à análise de casos, querendo ser pedagógica e inspirar aos jovens professores e pesquisadores da Faculdade de direito da UFRGS para que também realizem tais pesquisas e utilizem-se de casos concretos em suas aulas.

${ }^{10}$ O roteiro dos comentários foi o seguinte: I - Relatório, onde constará: - dados sobre a decisão (partes, Tribunal, data de julgamento, número etc.)- Resumo do conflito ou lide e das alegaçõesdestaque das normas legais citadas. Base citada ou aplicável de Direito Internacional Privado Resumo do decisum II - Análise da decisão - Destaque crítico dos principios e da linha jurisprudencial utilizada - Opinião do especializando sobre a decisão, quanto ao mérito e quanto à utilização ou não dos conhecimentos atuais do direito internacional. Fundamentalmente com a citação da doutrina, listando a bibliografia utilizada no final do comentário ou nas notas. ${ }^{11}$ Como ensina FARNSWORTH, Edward Allan, An introduction to the legal system of the United States, 3.Ed., Oceana Pub., New York, 1996, p. 19, o case method foi introduzido em 1871 por Cristopher Columbus Langdell, Professor da Havard Law School, em seu casebook on contracts, que levou ao abandono do tradicional lecture method. Segundo ALMEIDA Jr., João Mendes de, O ensino do Direito, in Revista de Direito Público, vol. 20, p. 133, o Prof. Langdell "começou a aplicar, em contraprodução aos velhos métodos usados nos Estados Unidos, do book-system e do lecturesystem, sistema de compêndio e da lição dogmática, um novo método denominado casesystem, cuja idéia fundamental consiste em formular os princípios juridicos sobre a análise de casos de jurisprudência."

12 Assim afirmam BAETA NEVES, Abilio Afonso e BAETA NEVES, Clarissa Eckert, As ciências sociais e a cooperação Brasil e Alemanha, in Retratos de Cooperação Científica e Cultural-40 anos do Instituto Cultural Brasileiro-Alemão, Valério Rohden (Coord.), EDIPUCRS, Porto Alegre, p. 259 e seg.

${ }^{13}$ Assim DAVID, René e JAUFFRET-SPINOSI, Camille, Les grands systèmes de droit contemporains, 9.Ed., Dalloz, Paris, 1988p. 33. 
Como ensina Eduardo Oliveira Leite, na investigação científica, é fundamental "que se determine, desde logo, um método de trabalho que, indicando etapas e processos a serem vencidos ordenadamente, conduzam à investigação dos fatos ou à procura da verdade. A determinação deste método não é atingível sem dificuldades e vai implicar incertezas, hesitações $e$, por vezes, erros, mas ainda que acarrete perda de tempo, é o caminho mais seguro de garantia do êxito de qualquer trabalho científico." ${ }^{14}$

A expressão método significa ao mesmo tempo via, caminho, direção (do grego, hodos) e fim, ligação, seqüência, resultado (meta).${ }^{15}$ Se o objeto determina o método, ${ }^{16}$ e o objeto ora estudado é o ensino do Direito, cabe, pois, a reflexão de como poderia ser este ensino realizado com mais efetividade e talvez com maior aproveitamento (meta) com a utilização, também no Brasil, do método alemão misto de solução de casos práticos como instrumento didático e pedagógico.

Como professora de Direito Internacional Privado brasileiro, observava muitas vezes que os alunos consideravam as suas normas quase como abstrações, de pouca utilidade na prática, motivo porque sempre fiz questão de incluir casos em sala de aula e demonstrar o método da análise da casos. Como escrevi na apresentação do livro de Harriet Zitscher ${ }^{17}$ :" Efetivamente, a dicotomia aparente entre a teoria e a praxis é um tema clássico da filosofia e do Direito, ${ }^{18}$ a discussão metodológica atual procura um caminho para a solução justa do caso concreto, ${ }^{19}$ alterando-se entre a tópica ${ }^{20}$, o processo argumentativo da filosofia discursiva ${ }^{21}$ e a nova legitimação da economia. ${ }^{22}$ Trata-se de um tempo de crise da própria dogmática jurídica, de seus fundamentos, de sua praxis

\footnotetext{
${ }^{14}$ LEITE, Eduardo de Oliveira, A Monografia Juridica, 3.ed., Ed. Revista dos Tribunais, São Paulo, 1997,p. 17.

${ }^{15}$ Veja sobre a oriegem grega da palavra e seus significados derivados, COMPARATO, Fábio Konder, Reflexões sobre o Método do ensino Jurídico, in Revista da Faculdade de Direito de São Paulo, vol. LXXIV, p. 119 e seg.

${ }^{16}$ Assim as palavras clássicas de Reinhold Zippelius: "Der Gegenstand bestimmt die Methode", ZIPPELIUS, Reinhold, Juristische Methodenlehre, 5.Aufl., Beck, München, 1990, p. 1.

17 Veja minha apresentação ao livro Zitscher, Harriet christiane, Metodologia do ensino jurídico com casos- Teoria e Prática, Ed. Del Rey, Belo Horizonte, 2001, p. 15 a 18.

${ }_{18}$ Veja FERRAZ Jr., Tércio Sampaio, Função Social da Dogmática Jurídica, Max Limonad, 1998, p. 18 a 24.

19 Sobre o tema veja LARENZ, Karl, Methodenlehre der Rechstwissenschaft, 6.Ed, Springer V., Heidelberg, 1991, p. 137 e seg.

20 Sobre o atual pensamento tópico, veja LARENZ, op. cit., p. 145 e Viehweg. Theodor, Tópica e Jurisprudência, Ministério da Justiça e UnB, Brasilia, 1979, p. 17 e seg.

${ }^{21}$ Veja Kaufmann, Arthur, Grundprobleme der Rechstphilosophie, Beck, Munique, 1994, p. 224 e seg.

${ }_{22}$ Veja como ZIMA, Peter, Moderne/Postmoderne, UTB, Francke, Tübingen, 1997.p. 61, identifica nos movimentos neo-liberais conservadores e economicistas (de direita) um dos braços da pósmodernidade. Assim também MINDA, Garry, Postmodern Legal Movements- Law and Jurisprudence at Century's end, New York University Press, New York, 1995.p. 83, identifica o movimento conservador de "direita" da análise econômica do Direito como pós-moderno. Na classificação de ROSENAU, Pauline Marie, Post-modernism and the social sciences, Princeton Univ. Press, Princenton, 1992, p. 53 , seriam "skeptical" pós-modernos. Veja sobre o movimento da análise econômica do direito como movimento pós-moderno, nosso trabalho, A crise científica do Direito na pós-modernidade e seus reflexos na pesquisa, in Rumos da Pesquisa-Múltiplas Trajetórias, Organizadoras Maria da Graça Krieger e Marininha Aranha Rocha Ed. UFRGS, Porto Alegre, 1998, p. 95 a 108.
} 
, dos conteúdos de formação profissional, da correção nas linhas do ensino e de adaptação às necessidades sociais emergentes. ${ }^{23}$ Dentre os métodos possíveis de ensino jurídico um trabalho com casos práticos adaptado ao estilo brasileiro pode ganhar espaço. ${ }^{24}$

As aulas das Faculdades de Direito no Brasil geralmente utilizam o método expositivo em aulas-magistrais, as quais se aproximam mais do monólogo, do que do diálogo construtivista e poucas vezes estimula a crítica. ${ }^{25}$ Não que a aula expositiva não possa ser aberta e criativa, ${ }^{26}$ ao contrário, oé em muitos países do mundo, como a própria Alemanha. Em minha experiência estudando no exterior, foi muito interessante observar que as aulas magistrais dos professores alemães modificaram-se e evoluíram fortemente do tempo em que fiz o meu Mestrado em Direito (LL.M.) na tradicional Universidade de Tübingen, Alemanha, isto é 1986-1987, até o ano de 1994, quando retornei a Heidelberg para escrever meu Doutorado em Direito, nesta também tradicional Universidade alemã. Em ambos os cursos pude assistir aulas magistrais (Vorlesungen) de famosos professores catedráticos pela manhã, todas partindo de casos práticos e acompanhadas por trabalhos com casos práticos pela tarde, com os professores assistentes (Fallbesprechungen). Entre 1994 e 1996, porém, pude observar em Heidelberg que o diálogo entre os estudantes e os professores era maior, assim como a participação dos alunos na sala de aula. É claro que em salas lotadas com 200 a 600 estudantes, poucos poderão participar. A participação do aluno se dá no trabalho com casos práticos, em que os grupos são de 10 a 20 por assistente, mas de qualquer maneira pude observar que o método de aulas magistrais com casos práticos tinha evoluído positivamente nestes 10 anos. Se Faculdades com mais de 600 anos podem evoluir, o que dizer de nossas jovens academias brasileiras. ${ }^{27}$ Incontestável que o caminho da evolução passa por uma valorização da figura do professor e recompensa de sua dedicação e evolução pessoal como cientista e professor universitário, ${ }^{28}$ assim como na melhoria das condições físicas para a pesquisa em Direito.

\footnotetext{
${ }^{23}$ Assim ensina, FERRAZ Jr., Tércio Sampaio, Função Social da Dogmática Jurídica, Max Limonad, 1998, p. 11.

${ }^{24} \mathrm{Veja}$ uma interessante apresentação da filosofia que está na base da teoria de Dworkin sobre 0 estudo dos hard cases, in NIORT, Jean-François e VANNIER, Guillaume, Sur la théorie du Droit de Dworkin: De l'interpretation des principes a leur application aux cas difficiles, in Droits (Paris), nr. 19, 1994 , p. 61 e seg.

${ }^{25}$ Veja críticas aos atuais métodos de ensino do Direito no Brasil, que não estariam ensinando 0 estudante a pensar, in FARIA, José Eduardo, Reforma do Ensino Jurídico, Ed. Sérgio Facris, Porto Alegre, 1987, p. 66.

${ }^{26}$ Veja BERBEL, Neusi A. Navas, Metodologia do Ensino Superior-Realidade e Significado, Papirus Ed., Campinas, 1994, p. 85 e seg.

${ }^{27}$ Veja a crítica quanto à falta de "modernização" no método de ensino do Direito no Brail, in CUNHA, Sérgio Sérvulo, Ensino Juridico-Método, in RT 395/433 e seg. Veja a critica construtiva ao ensino superior em geral no pais, CHASSOT, Attico, (Re)Pensando ações docentes: sobre como professoras e professores podem transformar o seu fazer pedagógico, in Melhoria do Ensino e Capacitação Docente, Vera Regina Pires MORAES (Org.), Editora da Universidade-UFRGS, Porto Alegre, 1996, p. 87 e seg.

${ }^{28} \mathrm{~V}$ eja severas críticas ao professor brasileiro, que ,segundo o autor, não pesquisa e dedica-se mais à advocacia ou a outra carreira juridica do que ao ensino, in MELLO FILHO, Álvaro de, Metodologia do Ensino Jurídico, Ed. Forense, Rio de Janeiro, 1984, p. 4 e do mesmo autor, Novas Diretrizes para o Ensino Jurídico, in Revista de Processo,nr. 74, p. 102 e seg.
} 
No sistema alemão, da discussão e reflexão sobre o caso, o estudante vai construindo seu conhecimento, assim como o professor o orienta nas conseqüências dogmáticas da solução proposta. Este método permite igualmente que pessoas com ainda pouca preparação jurídica e os "práticos" compreendam melhor a formação da solução jurídica, parecendonos apto a ser usado assim em quase todos os ramos do direito e em seus vários níveis do aprendizado. ${ }^{29}$ Fascinar os leigos pelo Direito, pela procura da Justiça e pela "vida" do e no Direito (law in action) é uma das possibilidades que se abre com o uso do método de casos no ensino jurídico. 30 "

Os casos de divórcios japoneses apresentados (e comentados) a seguir visam, pois, inspirar esta mudança metodológica em nossa Faculdade de direito, afinal, é quando olhamos o outro, o diferente que refletimos sobre os usos nossos, aquilo que é habitual e o que deveria mudar ou melhorar. Sendo assim, espero que esta 3 a parte desta edição especial possa ser de alguma utilidade aos colegas professores e estudantes.

${ }^{29}$ Veja sobre o possivel uso dos casos no ensino do Direito comparado, RHEINSTEIN, Max, Einführung in die Rechstvergleichung, Beck, Munique, 1987, p. 192 e 193.

${ }^{30}$ Veja sobre a dificuldade de interessar aos leigos atravès dos instrumentos clássicos e positivistas do Direito, ENGISH, Karl, Introdução ao pensamento juridico, Fundação Calouste Gulbenkian, Lisboa, 1988, p. 11. 